\title{
A cross-sectional survey on wounds in horses in New Zealand
}

\section{Theoret ${ }^{*} \dagger \S$, CF Bolwell*, CB Riley*}

${ }^{*}$ Equine Research Centre, Institute of Veterinary, Animal and Biomedical Sciences, Massey University, Palmerston North, 4442, New Zealand

†Current address: Comparative Tissue Healing Laboratory, Département de Biomédecine Vétérinaire, Faculté de Médecine Vétérinaire,

Université de Montréal, Saint-Hyacinthe, QC, J2S 7C6, Canada

$\checkmark$ Author for correspondence. Email: christine.theoret@umontreal.ca

\section{Supplementary Table 1. Questionnaire used to determine the frequency and type of skin wounds encountered by New Zealand veterinarians in their equine patients.}

1. Where is your practice located?

- $\quad$ Northland

- $\quad$ Auckland

- Waikato

- Bay of Plenty

- Gisborne

- Hawke's Bay

- Taranaki

- Manawatu-Wanganui

- Wellington

- Tasman

- Nelson

- Marlborough

- West Coast

- Canterbury

- Otago

- Southland

2. Approximately what proportion of your practice time is spent treating horses (as opposed to other species)?

- Less than $25 \%$

- $26-50 \%$

- $\quad 51-75 \%$

- $76-100 \%$

3. For how many years have you been practising equine medicine and surgery?

- Less than one year

- 1-2 years

- $\quad 3-5$ years

- 6-10 years

- $\quad 11-20$ years

- 21-30 years

- $31+$

4. How many veterinarians in your practice treat horses?

5. A-Does a particular veterinarian in your practice preferentially treat wounds in horses?

- Yes

- No 
6. Are you the veterinarian in your practice who preferentially treats wounds in horses?

- Yes

- No

7. On average, how many equine cases do you see each month ("case" defined as a horse requiring treatment for a disease or an injury, excluding routine work such as teeth floating, vaccination, deworming, reproduction visit, etc)?

8. On average, how many of the cases you see each month are wound related?

9. To your knowledge, how often do your clients treat wounds incurred by their horse without first consulting a veterinarian? Scale of Always, Frequently, Sometimes, Rarely, Never, Unsure

10. What type of wound are your clients likely to manage without consulting you? Scale of Always, Frequently, Sometimes, Rarely, Never, Unsure

- $\quad$ Skin only (head / neck)

- $\quad$ Skin only (body)

- $\quad$ Skin only (limb)

- $\quad$ Skin and underlying structures (head / body)

- $\quad$ Skin and underlying structures (body)

- $\quad$ Skin and underlying structures (limb)

- $\quad$ Other (please state below)

11. How often, during the year, do you treat wounds? Grid showing Spring, Summer, Autumn, Winter and Scale of Always, Frequently, Sometimes, Rarely, Never

12. How often do you treat the following types of wounds? Scale of Frequently, Sometimes, Rarely,

Never

- $\quad$ Skin only (head / neck)

- $\quad$ Skin only (body)

- $\quad$ Skin only (limb)

- $\quad$ Skin and underlying structures (head / body)

- $\quad$ Skin and underlying structures (body)

- $\quad$ Skin and underlying structures (limb)

13. In the case of deep wounds, how often are the following underlying structures involved? Scale of Frequently, Sometimes, Rarely, Never

- $\quad$ Body cavity (thoracic or abdominal)

- Joint space or tendon sheath

- $\quad$ Ligament or Tendon

- $\quad$ Sinus or eye

- Other

14. How often are the following anatomic locations the site of a wound? Scale of Frequently, Sometimes, Rarely, Never

- Foot

- $\quad$ Distal limb (below carpus / tarsus)

- $\quad$ Proximal limb (above carpus / tarsus)

- Body

- $\quad$ Head or neck 
15. In the case of wounds requiring more than one visit, what is the average number of times you treat the wound? Provide a number for each type of wound

- $\quad$ Skin only (head / neck)

- $\quad$ Skin only (body)

- $\quad$ Skin only (limb)

- $\quad$ Skin and underlying structures (head / body)

- $\quad$ Skin and underlying structures (body)

- $\quad$ Skin and underlying structures (limb)

16. What is the average duration of treatment (in weeks) required for the following types of wounds? Provide a number for each type of wound

- $\quad$ Skin only (head / neck)

- $\quad$ Skin only (body)

- $\quad$ Skin only (limb)

- $\quad$ Skin and underlying structures (head / body)

- $\quad$ Skin and underlying structures (body)

- $\quad$ Skin and underlying structures (limb)

17. On average, how often do the following types of wounds heal uneventfully once you have treated them (uneventfully = without infection OR dehiscence in the case of primary closure OR development of exuberant granulation tissue requiring surgical resection) Scale of Always, Frequently, Sometimes, Rarely, Never,

Unsure

- $\quad$ Skin only (head / neck)

- $\quad$ Skin only (body)

- $\quad$ Skin only (limb)

- $\quad$ Skin and underlying structures (head / body)

- $\quad$ Skin and underlying structures (body)

- $\quad$ Skin and underlying structures (limb)

18. What is your estimate of the total cost to the owner (of veterinary care and consumables) for managing the following types of wounds? Provide a number

- $\quad$ Superficial skin wound

- Deep wound involving underlying structures

19. On average, how long (number of weeks) will a horse be rested in relation to its wound?

- $\quad$ Superficial skin wound

- Deep wound involving underlying structures

20. On average, what percentage of the horses sustaining a wound will: Provide a percentage

- $\quad$ Return to their original performance level

- $\quad$ Achieve a lesser / reduced performance level

- $\quad$ Be forced to adopt an alternative career path

- Be retired

- Be euthanised

21. Rank the following ailments in decreasing order (most to least common) relative to the frequency with which you encounter them in your equine practice:

- Colic

- $\quad$ Digestive problem (other than colic)

- $\quad$ Eye disease

- Infectious disease

- Lameness 
- Metabolic disease

- $\quad$ Musculoskeletal disease (other than lameness)

- $\quad$ Neurologic disease

- $\quad$ Respiratory disease

- Reproductive disease

- Wound / trauma

- Other

22. Of your equine patients that die or are euthanised, what is the most common cause of death (rank from most to least common)?

- Colic

- $\quad$ Digestive problem (other than colic)

- $\quad$ Eye disease

- Infectious disease

- Lameness

- Metabolic disease

- $\quad$ Musculoskeletal disease (other than lameness)

- $\quad$ Neurologic disease

- Respiratory disease

- Reproductive disease

- Wound / trauma

- Other 